\title{
Nanogels of Poly(acrylic acid): Uptake and Release Behavior with Fluorescent Oligothiophene-Labeled Bovine Serum Albumin
}

\author{
Simona Argentiere ${ }_{1,2}^{1,2}$ Laura Blasi, ${ }^{1}$ Giuseppe Ciccarella, ${ }^{1,3}$ Giovanna Barbarella, ${ }^{4}$ \\ Roberto Cingolani, ${ }^{1,3}$ Giuseppe Gigli ${ }^{1,3}$ \\ ${ }^{1}$ National Nanotechnology Laboratories of CNR-INFM, Via Arnesano 16, Lecce I-73100, Italy \\ ${ }^{2}$ Istituto Superiore Universitario di Formazione Interdisciplinare-sez. Nanoscienze, Universita del Salento, \\ Via Arnesano 16, Lecce I-73100, Italy \\ ${ }^{3}$ Dipartimento di Ingegneria dell'Innovazione, \\ Università del Salento, Via Monteroni, Lecce I-73100, Italy \\ ${ }^{4}$ CNR, Area di Ricerca, ISOF, Bologna I-40129, Italy
}

Received 18 November 2008; accepted 26 October 2009

DOI 10.1002/app.31691

Published online 28 January 2010 in Wiley InterScience (www.interscience.wiley.com).

\begin{abstract}
Nanometer-sized poly(acrylic acid) (PAA) hydrogels were synthesized by emulsion polymerization of methyl acrylate and subsequent acidic hydrolysis. The nanohydrogel was characterized by spectroscopic methods (FTIR and ${ }^{1} \mathrm{H}-\mathrm{NMR}$ ) and scanning probe techniques, and their $\mathrm{pH}$-dependent swelling behavior was studied by dynamic light scattering. To determine the suitability of PAA nanogels as $\mathrm{pH}$-sensitive carriers for biomedical applications, uptake and release of an oligothiophene fluorophore and its albumin conjugated from PAA nanogels
\end{abstract}

were investigated as a function of $\mathrm{pH}$ by absorption and photoluminescence measurements. It was observed that uptake and release processes of both the oligothiophene and its conjugate could be controlled by changing the $\mathrm{pH}$ of the external solution. (c) 2010 Wiley Periodicals, Inc. J Appl Polym Sci 116: 2808-2815, 2010

Key words: stimuli-sensitive polymers; nanoparticles; emulsion polymerization; oligothiophene; uptake and release

\section{INTRODUCTION}

Nanogels have recently attracted significant attention in the controlled release technology for diagnostic and therapeutic applications. ${ }^{1-4}$

Because of their high water content and carbonbased network structure, these systems represent the closest synthetic approximation to biological tissue and materials. ${ }^{5}$ Moreover, their chemical and physical properties can be tailored with a high degree of control, according to the selected delivery route. ${ }^{6,7}$ Finally, in the presence of proper functional groups, they have the property of undergoing reversible volume phase transitions in response to environmental factors, such as temperature, ionic strength, and $\mathrm{pH}^{8,9}$

Ionizable functional groups bound to the polymeric chains give $\mathrm{pH}$-responsivity to these materials. In particular, poly(acrylic acid) (PAA)-based polymers exhibit a swelling behavior depending on environmental $\mathrm{pH}$ and ionic strength, due to their carboxylic groups. ${ }^{10,11}$ Thus, the $\mathrm{pH}$-sensitive nano-

Correspondence to: G. Ciccarella (giuseppe.ciccarella@ unisalento.it).

Journal of Applied Polymer Science, Vol. 116, 2808-2815 (2010)

(c) 2010 Wiley Periodicals, Inc. gels exploit the $\mathrm{pH}$ changes within the body to direct the response towards a specific target. ${ }^{12}$

The $\mathrm{pH}$-sensitive nanogels have been successfully used for the encapsulation of several drugs and proteins, whose limited stability and high molecular weight make very difficult for their administration via different routes. ${ }^{5,9,13,14}$ For example, PAA nanogels have been investigated as candidates for the oral protein delivery as they provide protection from gastrointestinal tract conditions, whose $\mathrm{pH}$ values range from less than 3 in stomach to about 8 in small intestine. ${ }^{14,15}$ In addition, acrylic acid based polymers have recently been used to enhance the endosomal release of biotherapeutics into the cytoplasm, using strategies that mimic the membranedisruptive peptides of viruses. ${ }^{16,17}$

The advantages of using nanogels arise from their main properties. First, they have a large specific surface, which increases the interactions with physiological compartments ${ }^{18}$ and enhances the solubility and bioavailability of loaded drugs. ${ }^{19}$ Second, because of their small size, they can overcome anatomic barriers and reach even small capillaries. ${ }^{20}$ Finally, PAA-based polymers are nontoxic and biodegradable, and recent in vivo studies on PAA-based hydrogels suggest they are well tolerated. ${ }^{21-23}$ 
However, so far few studies have been conducted about uptake and delivery processes of drugs and proteins with nanogels. Polyethyleneimine-based nanogels have been used as nonviral vectors for the targeted gene delivery and poly( $\mathrm{N}$-isopropylacrylamide) nanogels were studied to evaluate the driving forces in the uptake and release of bovine serum albumine (BSA) and $\gamma$-globulins. ${ }^{4,24-26}$ Recently, nanogels consisting of an analogue of linear polyethylene oxide were synthesized and tested as carriers for controlled drug delivery. ${ }^{3}$ To the best of our knowledge, no uptake and release experiments of drugs/proteins with PAA nanogels are reported in literature.

The aim of this article is the understanding of the uptake and release processes into and from PAAbased nanogels. To this purpose, we used an oligothiophene fluorophore (TF) and its conjugate with BSA as model protein. The PAA nanogels were synthesized by emulsion polymerization of methyl acrylate and subsequent acidic hydrolysis, and characterized by dynamic light-scattering (DLS), FTIR, and ${ }^{1} \mathrm{H}-\mathrm{NMR}$. The synthesized nanogels were deposited on a glass support and further characterized by scanning probe techniques. Then the PAA nanohydrogels were successfully used for the $\mathrm{pH}$ controlled uptake and subsequent release of TF and its conjugate with BSA. The photostability, fluorescence intensity, and color tunability of both oligothiophenes and their conjugates will make them useful for a wide number of research fields, such as biolabeling and tracking of protein delivery. ${ }^{27,28}$

\section{EXPERIMENTAL}

\section{Materials}

Methyl acrylate (MA), sodium dodecyl sulfate (SDS), ammonium persulphate (APS), and sodium thiosulphate (STS), 3-(4,5-dimethyl-2-thiazolyl)-2,5diphenyl-2H-tetrazolium bromide (MTT salt 135038), as well as all the disposable materials and products needed for cell culture were purchased from Sigma Aldrich. Deionized water with a resistivity of $18.0 \mathrm{M}$ $\Omega \mathrm{cm}$ was used in the synthetic procedure.

5"-Methylsulfanyl-[2,2', 5', 2" ]terthiophene-5-carboxylic acid 2,5-Dioxopyrrolidin-1-yl Ester (TF, Fig. 1), ${ }^{28}$ and its bovine serum albumin conjugate (BSA-TF $)^{29}$ were used as received, and their chemical and optical properties, as well as their synthetic procedure are reported elsewhere. ${ }^{28,29}$

\section{Synthesis and characterization of poly(methyl acrylate) nanogels}

The poly(methyl acrylate) (PMA) nanogel was synthesized by emulsion polymerization. ${ }^{11}$ Small

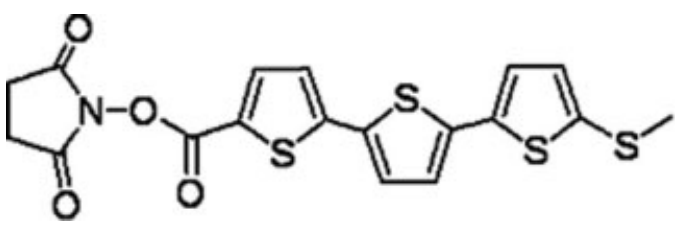

Figure 1 Molecular structure of OTF.

unilamellar vesicles were prepared by mixing SDS $(250 \mathrm{mg}, 0.867 \mathrm{mmol})$ and water $(50 \mathrm{~mL})$ at room temperature (R.T.) and sonicating them for $15 \mathrm{~min}$. This solution was heated to $\sim 65^{\circ} \mathrm{C}$ in nitrogen atmosphere. The initiating agents APS $(10 \mathrm{mg}$, $0.0438 \mathrm{mmol})$ and STS $(10 \mathrm{mg}, 0.0403 \mathrm{mmol})$ as well as MA monomer $(12.5 \mathrm{~g}, 0.145 \mathrm{~mol})$ were added to the SDS vesicles dispersion. The solution turned turbid within $10 \mathrm{~min}$, indicating the successful beginning of the radical polymerization. The polymerization was carried out for $2 \mathrm{~h}$ and stopped by cooling down in an ice bath. The reaction mixture was transferred to centrifugal filter devices (Amicon Ultra-15, $10 \mathrm{kD}$, Millipore Bedford, MA) and centrifuged at 5000 relative centrifugal force for $1 \mathrm{~h}$, to remove decomposed initiating agents, excess surfactant, and unreacted monomers, as well as to concentrate the sample by ultrafiltration.

To induce the hydrolysis of the methyl ester groups, the PMA nanogels were dissolved in THF and irradiated in a microwave oven (input power $600 \mathrm{~W}, 78^{\circ} \mathrm{C}$ ) in the presence of a catalytic amount of trifluoroacetic acid. ${ }^{30}$ After $1 \mathrm{~h}$, the pale yellow precipitate was resuspended in deionized water, indicating that PAA nanogels were obtained.

\section{Chemical characterization of PMA and PAA nanogels: FTIR and ${ }^{1} \mathrm{H}-\mathrm{NMR}$}

The PMA and PAA nanogels were freeze-dried using a LIO-5P apparatus (Cinquepascal s.r.l., MI, Italy). The FTIR spectra were acquired $(\mathrm{KBr})$ by means of a Jasco FT/IR-6300.

${ }^{1} \mathrm{H}-\mathrm{NMR}$ spectra of PMA and PAA nanogel were obtained on a Bruker spectrometer operating at frequency of $400 \mathrm{MHz}$. The chemical shifts are reported in parts per million downfield $(\delta)$ from TMS. PMA nanogel $\left(\mathrm{D}_{2} \mathrm{O}\right.$ in water, $\left.10 \%, \mathrm{v} / \mathrm{v}\right): \delta 1.60-2.50 \mathrm{ppm}$ $\left(\mathrm{m}, 3 \mathrm{H}, \mathrm{CH}_{2} \mathrm{CH}\right), \delta 3.67 \mathrm{ppm}\left(\mathrm{s}, 3 \mathrm{H}, \mathrm{CH}_{3}\right)$. PAA nanogel $\left(\mathrm{CDCl}_{3}\right): \delta 3.38-3.68 \mathrm{ppm}\left(\mathrm{m}, 3 \mathrm{H}, \mathrm{CH}_{2} \mathrm{CH}\right)$.

\section{Dynamic light scattering measurements}

Hydrodynamic diameter of PMA and PAA nanoparticles was measured with a Zetasizer Nano Series (Malvern Instrument) at a fixed angle of $90^{\circ}$. Nanogel was diluted in $1.0 \mathrm{mM}$ borate buffer and the $\mathrm{pH}$ was fixed at different values by adding submicroliter amounts of $0.5 \mathrm{M} \mathrm{NaOH}$ and $0.5 \mathrm{M} \mathrm{HCl}$. The 
suspension was filtered through a Millipore membrane filter $(0.22 \mu \mathrm{m}$ pore size) to remove dust particles. All the measurements were carried out at R.T. and every sample was measured five times. Polystyrene nanospheres $(60 \pm 5 \mathrm{~nm}$; Duke Scientific Corp.) were used to calibrate the instrument.

\section{Scanning probe microscopy measurements}

The topographic features of PAA nanogels deposited onto glass support were investigated in air with an atomic force microscope (AFM) SMENA-B (NTMDT) working in semicontact-mode in air $\left(20^{\circ} \mathrm{C}\right.$, relative humidity $30 \%$ ). In this mode, the force of pressure of the cantilever allows to work with soft materials such as polymers and bioorganics, which can be easily damaged. We used MPP-12120 silicon probes (Veeco).

Phase-contrast images in water were acquired by an AFM (XE-100, PSIA, Korea) operating in true noncontact mode. The cantilever used for fluid AFM was an NSC36 (PSIA, Korea).

\section{Assessment of cytotoxicity by MTT assay}

The cytotoxic effect of the PAA nanogels was tested on Jurkat cells (human acute T-lymphoblastic leukemia cells) using the 3-(4,5-dimethyl-2-thiazolyl)-2,5diphenyl-2 $\mathrm{H}$-tetrazolium bromide assay (MTT assay). The cells were cultured in RPMI 1640 medium supplemented with $10 \%$ heat-inactivated calf serum and $100 \mathrm{U} / \mathrm{mL}$ penicillin. The cells were maintained in an incubator with a constant humidified atmosphere of $5 \%$ at $37^{\circ} \mathrm{C}$, and routinely examined for mycoplasma contamination. Briefly, cells were seeded $\left(8 \times 10^{4}\right.$ cells/well $)$ in 12-well plates and cultured in medium containing the PAA nanogel at different final concentrations of 1 to $0.01 \mathrm{~g} / \mathrm{L}$. After incubation for 48-96 h, $1 \mathrm{~mL}$ MTT solution $(1 \mathrm{mg} / \mathrm{mL})$ was incubated for $3 \mathrm{~h}$ with the treated cells at $37^{\circ} \mathrm{C}$. The MTT, reduced by the mitochondrial reductase of vital cells, formed a dark insoluble product, the formazan. At this point, the dark pellet was dissolved in DMSO, leading to a violet solution whose absorbance at $570 \mathrm{~nm}$ was determined by UV-vis spectrophotometer. The absorbance value can be correlated to the percentage of vital cells by comparing the data of the treated cells with those of the control cells (i.e., with no nanogels added into medium). All determinations were carried out in triplicate.

\section{Absorption and photoluminescence measurements}

Absorbance and fluorescence spectra were recorded by Cary 5000 UV-Vis-NIR Spectrophotometer and
Cary Eclipse Fluorescence Spectrophotometer (Varian), respectively.

\section{Uptake and release of TF into PAA nanogels}

To evaluate the nanogel uptake behavior at two different expansion states, two incubation solutions were prepared at different $\mathrm{pH}$ values (Solution a, $\mathrm{pH} 4.5$ and Solution b, pH 7.0). The incubation solution was prepared by mixing nanogel $(0.1 \mathrm{~g} / \mathrm{L})$, TF $\left(3.66 \times 10^{-3} \mathrm{~g} / \mathrm{L}\right)$, and Tween $20(0.1 \%, \mathrm{w} / \mathrm{v})^{29}$ in a $1.0 \mathrm{mM}$ borate buffer. The volume for each sample was $0.5 \mathrm{~mL}$. After incubating for $2 \mathrm{~h}$, the TF-loaded nanogels were purified from exceeding TF molecules by gel filtration on Sephadex G-25 column (NAP-25, GE-Healthcare). ${ }^{31,32}$ Two different borate buffers $1.0 \mathrm{mM}$, at $\mathrm{pH} 4.0$ and 5.0 were used for the elution of TF/nanogel mixture at $\mathrm{pH} 4.5$ and 7.0, respectively.

Absorbance and fluorescence spectra of the loaded nanogels $\left(\lambda_{\mathrm{ex}}=373 \mathrm{~nm}\right.$ and $\left.\lambda_{\mathrm{em}}=560 \mathrm{~nm}\right)$ were measured in borate buffered solution in triplicate for every sample.

Control experiments on TF and nanogel were performed to assess the suitability of NAP-25 column for the purification of nanogel/TF solutions.

The uptake of TF by the nanogel (milligram of TF per milligram of nanogel) was calculated according to the eq. (1):

$$
\begin{aligned}
\text { Uptake : } \quad(\mathrm{mg} \text { of TF } / \mathrm{mg} \text { of nanogel }) \\
\quad=A_{n} A_{c}^{-1} V_{\text {sys }} C_{i}(\text { mg of nanogel })^{-1}
\end{aligned}
$$

where $A_{c}$ and $A_{n}$ are respectively, the absorbance of the control and of the nanogel after the uptake process, $V_{\text {sys }}$ is the total volume of the system, and $C_{i}$ is the initial concentration of TF. ${ }^{33,34}$

Release experiments were carried out at $\mathrm{pH}$ 9.0, as at this $\mathrm{pH}$ the nanogels are swollen, allowing the release of TF through the enlarged meshes of their

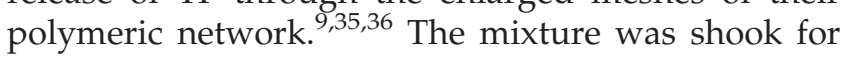
$2 \mathrm{~h}$ at R.T. and then purified by gel filtration on a NAP-25 column (borate buffer $1.0 \mathrm{mM}, \mathrm{pH} 9.0$ ). The spectral properties of the nanogels after release $\left(\lambda_{\text {ex }}\right.$ $=373 \mathrm{~nm}$ and $\lambda_{\mathrm{em}}=560 \mathrm{~nm}$ ) were measured in borate-buffered solution.

\section{Uptake and release of BSA-TF into PAA nanogels}

Uptake experiments of BSA-TF were carried out similarly to the procedure reported for TF. Two different solutions were prepared at $\mathrm{pH} 4.5$ (Solution c) and $\mathrm{pH} 7.0$ (Solution d). Nanogel $(0.1 \mathrm{~g} / \mathrm{L})$ and BSA-TF $\left(3.66 \times 10^{-3} \mathrm{~g} / \mathrm{L}\right)$ were mixed in borate buffer $(1.0 \mathrm{mM})$. After incubating for $2 \mathrm{~h}$, the BSATF-loaded nanogel was purified from unloaded 


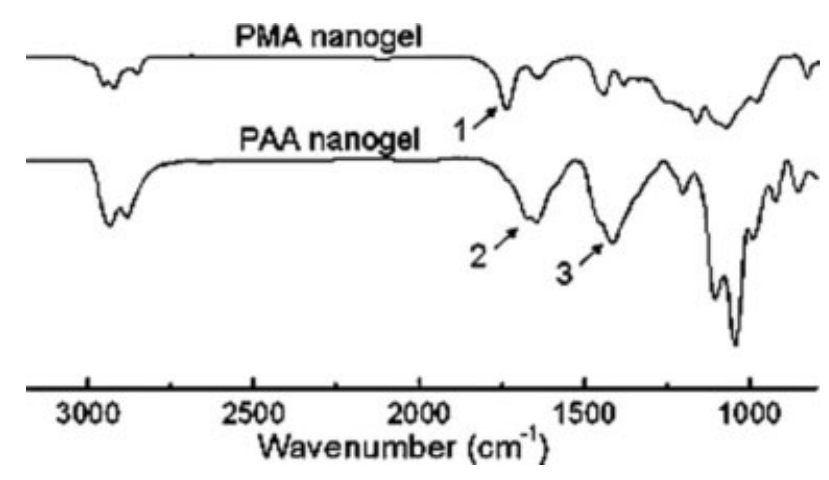

Figure 2 FTIR spectra of PMA and PAA nanogel. Peak 1: ester $\mathrm{C}=\mathrm{O}$ stretching; Peak 2: asymmetric carboxylate stretching; Peak 3: symmetric carboxylate stretching.

bioconjugates by gel filtration on a NAP- 25 column. Two different borate buffers $(1.0 \mathrm{mM})$ at $\mathrm{pH} 4.0$ and 5.0 were used for the elution of BSA-TF/nanogel mixture at $\mathrm{pH} 4.5$ and 7.0, respectively. Two reference solutions of BSA-TF and nanogel were eluted separately by gel filtration, demonstrating the suitability of the separation condition. Absorbance and fluorescence spectra of the BSA-TF-loaded nanogels $\left(\lambda_{\text {ex }}=373 \mathrm{~nm}\right.$ and $\left.\lambda_{\text {em }}=485 \mathrm{~nm}\right)$ were measured in borate-buffered solution in triplicate for every sample.

For the release experiment, the suspension of nanogels loaded with BSA-TF was equilibrated at $\mathrm{pH}$ 9.0, shook for $2 \mathrm{~h}$ at R.T., and then eluted in a NAP-25 column (borate buffer $1.0 \mathrm{mM}$, pH 9.0). The spectral properties of the nanogels after release were recorded in borate-buffered solution $\left(\lambda_{\text {ex }}=373 \mathrm{~nm}\right.$ and $\lambda_{\mathrm{em}}=485 \mathrm{~nm}$ ).

\section{RESULTS AND DISCUSSION}

\section{PMA and PAA nanogel synthesis}

Emulsion polymerization is a rather complex process involving several steps such as nucleation, growth, and stabilization of polymer particles in combination with various colloidal phenomena. ${ }^{37,38}$

In the PMA synthetic procedure, the SDS concentration was above its critical micelle concentration in water, ${ }^{39}$ to ensure that the particles were almost all formed via micellar nucleation. ${ }^{38}$ Further, ultrasonic radiation was applied to the system to induce acoustic degasification.

Saway and coworkers prepared microgels by emulsion polymerization, demonstrating that the extent of $\mathrm{pH}$-dependent swelling of the crosslinked gel was much less than that of the noncrosslinked one. ${ }^{11}$ According to these results, any crosslinker agent has been used in the reported synthetic procedure.

\section{Chemical characterization of PMA and PAA nanogels: FTIR and ${ }^{1} \mathrm{H}-\mathrm{NMR}$}

The hydrolysis of PMA nanogels was monitored by FTIR and ${ }^{1} \mathrm{H}-\mathrm{NMR}$. The comparison between the FTIR spectra of PMA and PAA nanogels revealed the disappearance of a peak at $1738 \mathrm{~cm}^{-1}$ — characteristic for the carbonyl stretching of the methyl ester groups-and the appearance of two new peaks at 1650 and $1416 \mathrm{~cm}^{-1}$, arising from respectively, the asymmetric and symmetric carbonyl stretching of the carboxylate groups (Fig. 2).

The successful outcome of the hydrolysis reaction was confirmed by considering the ${ }^{1} \mathrm{H}$-NMR spectra of PMA and PAA nanogels, as the peak at the chemical shift of 3.67, due to the methoxy protons of PMA, disappears in the spectrum of PAA nanogel, indicating that the PMA conversion rate was $100 \%$.

\section{Cytotoxic assay}

To evaluate the cytotoxicity of PAA nanogels, in vitro cytotoxicity tests against T-lymphoblastic Jurkat cells were conducted. Cell viability measurements were conducted using the MTT assay. The survival of Jurkat cells treated with PAA nanogels at concentrations of $0.01,0.1$, and $1 \mathrm{~g} / \mathrm{L}$ are shown in Figure 3. The trends show clearly that all tested concentrations slightly decreased cell survival to about $91 \pm 5 \%$ of the control value, even after $96 \mathrm{~h}$ of treatment of the cells with PAA nanogels. Using the MTT assay, the polymer-treated cells were able to metabolize the mitochondrial substrate MTT by conversion into formazan crystals, and no damage was

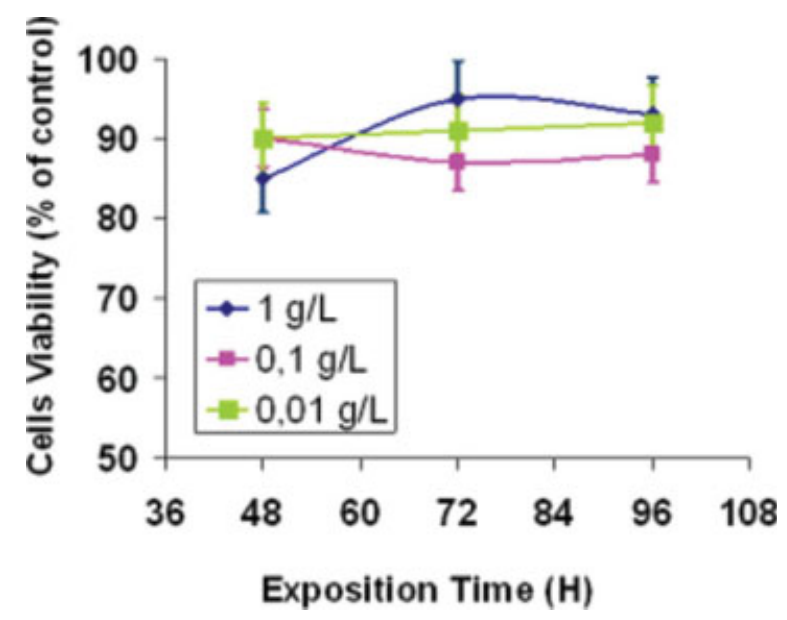

Figure 3 Effect of PAA nanogels at three different concentrations on cell viability of T-lymphoblastic cells detected by MTT test. The percentage of cell viability was calculated by comparing the data of the treated cells with those of the control cells. All values are reported as the mean \pm standard error of the mean. [Color figure can be viewed in the online issue, which is available at www. interscience.wiley.com.] 


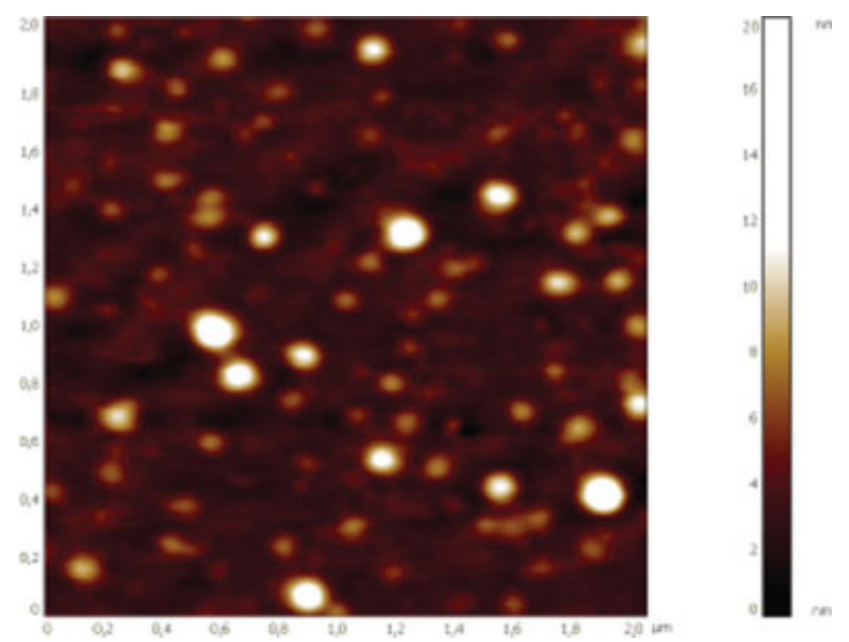

Figure 4 Air TM-AFM of PAA nanogels deposited onto glass support. Scan size $=2 \times 2 \mu \mathrm{m}^{2}$, vertical scale $=$ $20 \mathrm{~nm}$, scanning frequency $=1.19 \mathrm{~Hz}$. [Color figure can be viewed in the online issue, which is available at www. interscience.wiley.com.]

observed at the intracellular level. This metabolic activity of cells is an appropriate technique for assessing the number of viable cells, since damaged or dead cells are devoid of any mitochondrial dehydrogenase activity. ${ }^{40}$

\section{Scanning probe characterization}

The AFM analysis provides information concerning the appearance, the homogenity of nanogels deposited on solid substrate at nanometer scales and their bulk or cluster properties. A typical air TM-AFM image is shown in Figure 4; hydrogel nanoparticles are present in the deposited layers, exhibiting an average height of about $13 \pm 4 \mathrm{~nm}$ and a diameter of $85 \pm 10 \mathrm{~nm}$.

Figure 5 shows the resulting phase-contrast image, obtained by imaging the sample in bidistilled water (namely in the hydrated state). Phase contrast can be obtained on heterogeneous surfaces because of the different interactions between the tip and different regions of the samples. It has been shown that major contributors to phase contrast are viscoelastic properties and adhesion. ${ }^{41}$ In this case, the shape and the relative height $(20 \pm 3 \mathrm{~nm})$ of the observed features suggested that the nanohydrogel slightly swelled because of the aqueous environment.

\section{PAA nanogel characterization in solution: Dynamic light scattering}

Hydrogels containing weak acid carboxylic groups change their swelling and permeability properties in response to $\mathrm{pH}$. In particular, under basic conditions, negative charges on the particle surface increase due to the formation of acrylate groups,

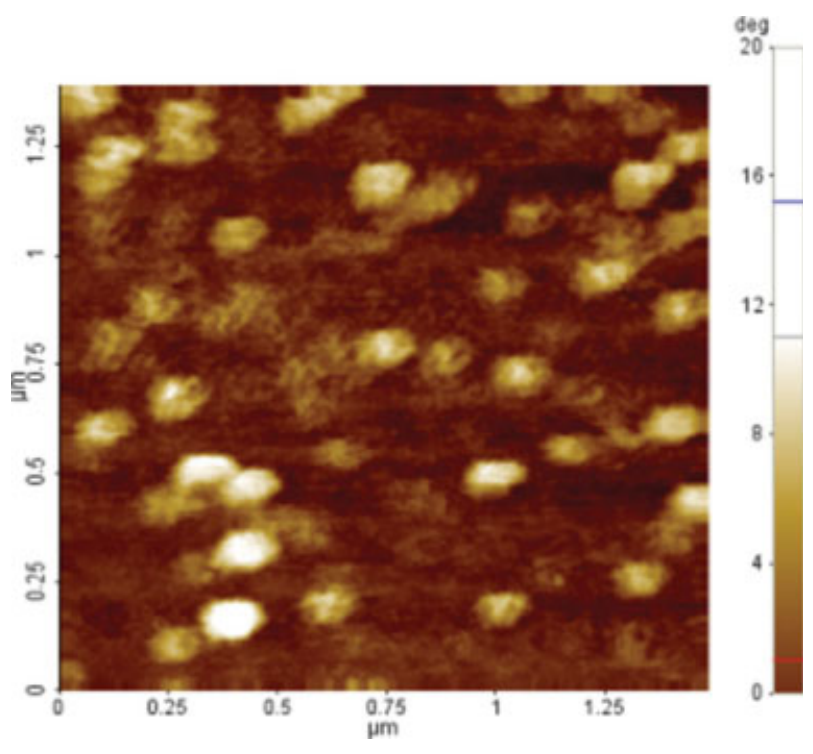

Figure 5 Phase image of PAA nanogel in water. Scan size $=1.5 \times 1.5 \mu^{2}$, vertical scale $=20^{\circ}$, scanning frequency $=0.7 \mathrm{~Hz}$. [Color figure can be viewed in the online issue, which is available at www.interscience. wiley.com.]

causing the expansion of the nanogel. ${ }^{11,42}$ To this purpose, the DLS technique was selected to check the nanogel hydrodynamic radius in solution over a wide range of $\mathrm{pH} .{ }^{11}$

The purified PMA precursor nanogel was measured and its average diameter resulted $70.0 \pm$ $5.0 \mathrm{~nm}$. Then, after the selective surface hydrolysis, DLS measurements were performed by suspending PAA nanogels in $1.0 \mathrm{mM}$ borate buffer solutions with different $\mathrm{pH}$ values. Figure 6 shows the plot of the hydrodynamic diameter versus $\mathrm{pH}$. Thus, the more basic the $\mathrm{pH}$ solution, the larger is the nanogel diameter, which reaches the maximum value of $120.0 \pm 5.0 \mathrm{~nm}$ at $\mathrm{pH} 9.0$.

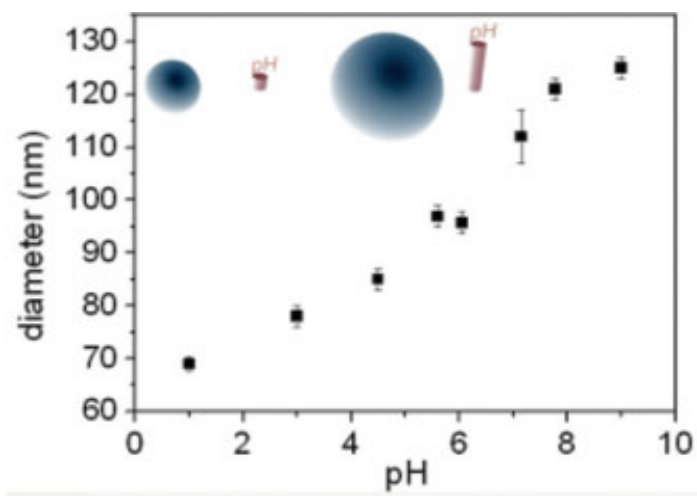

Figure 6 Plot of the hydrodynamic diameter of nanogel particles versus the $\mathrm{pH}$ of the surrounding solution. Inset. Schematic representation of PAA nanogel swelling as a function of the $\mathrm{pH}$. [Color figure can be viewed in the online issue, which is available at www.interscience.wiley. com.] 

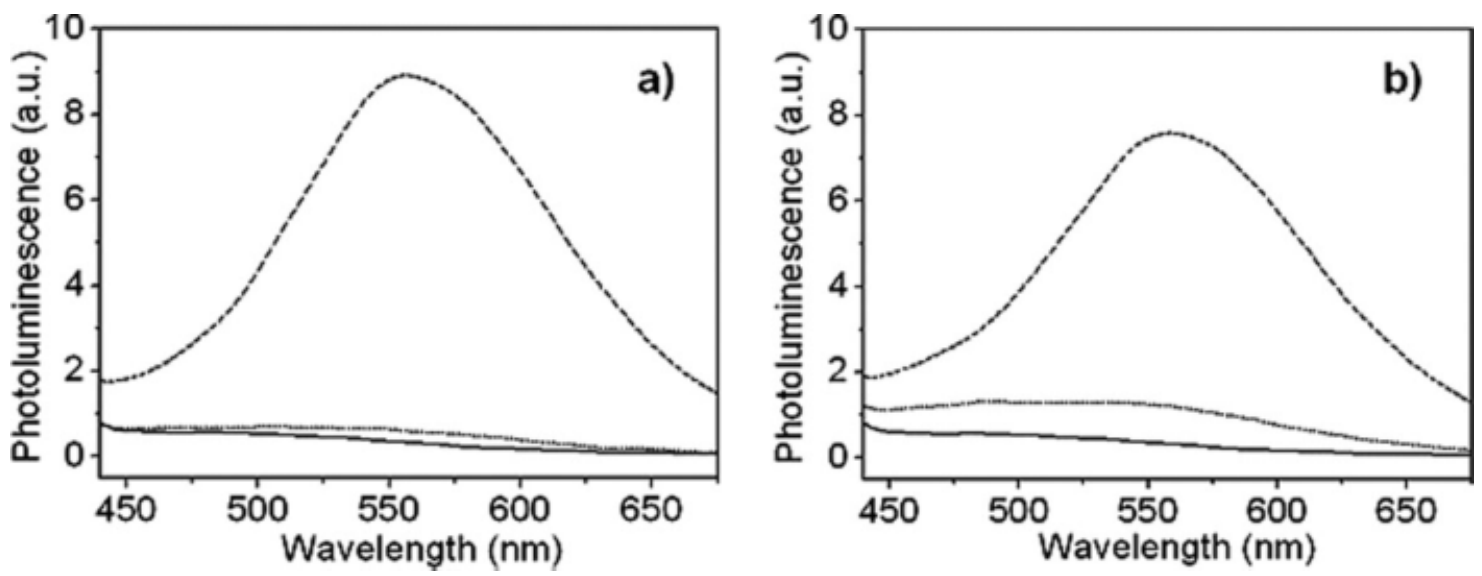

Figure 7 (a) Photoluminescence spectra of the PAA nanogel (straight line) at the same concentration of the experiment $(0.1 \mathrm{~g} / \mathrm{L})$, after the uptake of TF at $\mathrm{pH} 4.5$ (dash line) and the release experiment (dot line). $\lambda_{\text {ex }}=373 \mathrm{~nm}$. (b) Photoluminescence spectra of the nanogel $(0.1 \mathrm{~g} / \mathrm{L}$, straight line), after the TF uptake at $\mathrm{pH} 7.0$ (dash line) and the release experiment (dot line). $\lambda_{\text {ex }}=373 \mathrm{~nm}$.

\section{Nanogel uptake and release behavior}

As the nanogel undergoes a swelling from 70 to 120 $\mathrm{nm}$ in response to an increase of the $\mathrm{pH}$ solution, the pore size of the network becomes larger, allowing the flow of water soluble molecules or proteins. ${ }^{35,36}$ When the $\mathrm{pH}$ is reduced, the permeability of the nanohydrogel decreases, inducing the entrapment of solutes inside the nanogel network. Differently, at basic $\mathrm{pH}$ values, the volume and the permeability of the nanohydrogel increased once again, allowing the release of the previously trapped molecules from the polymer matrix and their diffusion in the external solution. ${ }^{35,36}$

Uptake experiments were performed at $\mathrm{pH} 4.5$ and 7.0 with both the TF (Fig. 1) and its albumin conjugate (BSA-TF). ${ }^{28,29}$ TF is hydrophobic and $\mathrm{pH}-$ insensitive, whereas its conjugate with BSA is $\mathrm{pH}$ sensitive and its charge is correlated to the isoelectric point of the protein ( $\mathrm{pI}$ 4.7). ${ }^{43}$ The maximum emission wavelength of the conjugate BSA-TF was reported to be blue shifted by about $50 \mathrm{~nm}$ compared with that of free $\mathrm{TF}^{29}$

Figure 7 reports the fluorescence measurements of $\mathrm{TF}$ encapsulated into the nanogels. The spectra were acquired after a purification performed by gel filtration chromatography, to remove the free exceeding oligothiophenes and their spectral contribute. It was observed that running the uptake experiment either at acidic $\mathrm{pH}$ of 4.5 [Fig. 7(a)] or at neutral $\mathrm{pH}$ of 7.0 [Fig. 7(b)], the uptake of TF was substantially the same, indicating that the uptake mechanism is $\mathrm{pH}$ independent. According to the eq. (1), the uptake was 0.014 and 0.017 (mg TF/mg nanogel) for the experiments run at the $\mathrm{pH}$ values of 4.5 and 7 , respectively. These data could be explained by assuming that uptake and release processes for nonpolar, hydrophobic solutes such as TF proceed throughout hydrophobic interactions between the solutes and the lipophilic domain of the nanogel. ${ }^{44}$

Further, the comparison between uptake and release data, as depicted in Figure $7(a, b)$, clearly demonstrated the diffusion of the oligothiophene in the external solution.

In the experiment with BSA-TF at $\mathrm{pH} 4.5$, the albumin conjugate had a positive charge $(\mathrm{pH}<\mathrm{pI})$, and nearly $50 \%$ of carboxylic groups onto the nanogel surface were dissociated ( $\mathrm{pH} \sim \mathrm{pKa}$ of the nanogel). ${ }^{42}$ When the BSA-TF uptake was run at $\mathrm{pH} 7.0$, both the BSA probe and nanogel were negatively charged $(\mathrm{pH}>\mathrm{pI})$. In Figure 8(a), the photoluminescence spectra of the loaded BSA-TF at pH 4.5 and 7.0 are reported. In particular, the BSA-TF uptake occurred at $\mathrm{pH} 4.5$ with an uptake of $0.036 \mathrm{mg}$ of BSA-TF per mg of nanogel, whereas at $\mathrm{pH} 7.0$ the loaded amount of the fluorescent conjugate was much lower (0.008 mg of BSA-TF/mg nanogel).

These data could be explained by assuming that at $\mathrm{pH} 4.5$ the net positive charge of the BSA conjugate provides a driving force for its uptake into the negatively charged gel via ion-exchange. ${ }^{45}$ The uptake process via ion-exchange was absent while

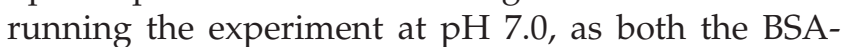
$\mathrm{TF}$ and the nanogel had a negative charge. As recent studies on acrylate-based microgels used the ionexchange theory, it should be deduced that nanogels behave similarly to microgels. ${ }^{33-36,42}$

In fact, in PAA nanogel the counterions bound to the carboxylate groups can be exchanged with positive charges from the external solution, according to the Donnan equilibrium. ${ }^{34-36,42,46}$ After the absorption phase, the cations can be included into the nanogel network by physical inclusion if there is a dimensional compatibility between the average pore size and the molecule diameter. ${ }^{34}$ Thus, it can be 

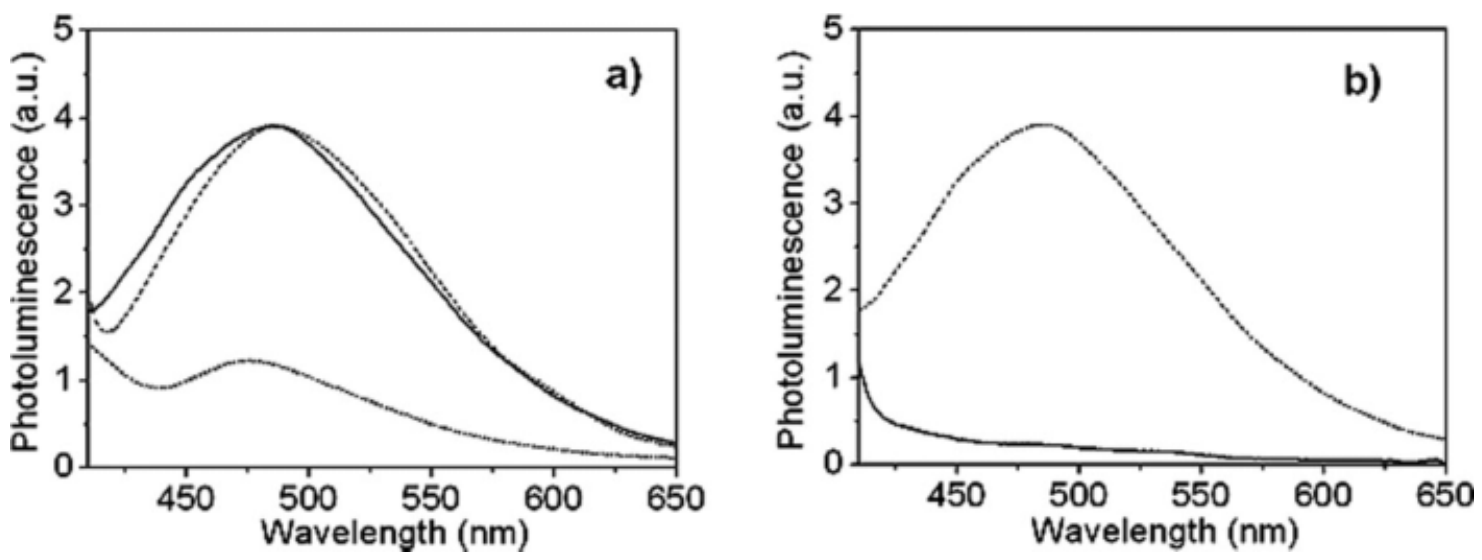

Figure 8 (a) Photoluminescence spectrum of the BSA-TF encapsulated in PAA nanogel after incubation at pH $=4.5$ (dash line) and at $\mathrm{pH}=7$ (dot line). It is also indicated the fluorescence spectra of the BSA-TF at the concentration used in the experiment $\left(\mathrm{C}=3.66 \times 10^{-3} \mathrm{~g} / \mathrm{L}\right.$, straight line). (b) Photoluminescence spectrum of the BSA-TF encapsulated in PAA nanogel after the incubation at $\mathrm{pH} 4.5$ (dash line) and the release experiment (straight line). $\lambda_{\text {ex }}=373 \mathrm{~nm}$.

estimated that the mesh size of the PAA nanogel should be larger than $4 \mathrm{~nm}$, which corresponds to the diameter of $\mathrm{BSA}^{47}$ An accurate study on the evaluation of the mesh size is still in progress.

Figure 8(b) shows the release experiment run with the nanogels previously incubated in the presence of BSA-TF at $\mathrm{pH}$ 4.5. The nanogels were separated from the released BSA-TF by gel filtration. Absorbance and fluorescence spectra indicate the complete release of the oligothiophene-BSA derivative from the nanogel network.

Figure 9 summarizes the uptake data of TF and BSA-TF into nanogel, running the uptake experiment at the $\mathrm{pH}$ values of 4.5 and 7.0. It is evident that the uptake of the $\mathrm{pH}$-insensitive TF occurs in a quite $\mathrm{pH}$-insensitive way. Vice versa, using a $\mathrm{pH}$-dependent bioconjugate such as BSA-TF uptake seems to be strictly $\mathrm{pH}$-dependent. This can be ascribed to the different uptake mechanisms described above.

These results can be expressed in terms of encapsulation efficiency (E.E.), which is the weight ratio of encapsulated to the total TF (or BSA-TF). ${ }^{48}$ The

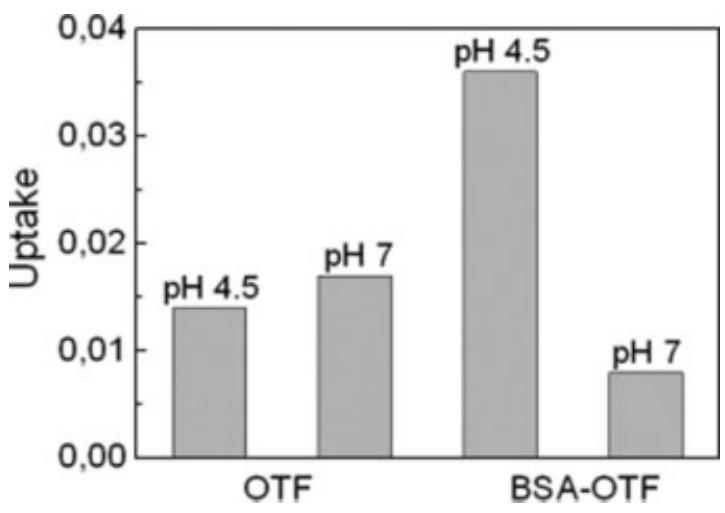

Figure 9 Plot of the uptake data into nanogels (mg fluorophore/mg nanogel) concerning the uptake experiments run with OTF and BSA-OTF.
E.E. values obtained running the TF and BSA-TF uptake experiments at the $\mathrm{pH}$ of 4.5 and 7.0 are reported in Table I.

The encapsulation efficiency values are comparable to those mentioned in literature both for PAA as well as for other polymeric nanoparticles. ${ }^{49-51}$

\section{CONCLUSIONS}

In this study, PAA nanogels were used for the $\mathrm{pH}$-controlled uptake and release of the oligothiophene TF and its conjugate BSA-TF.

First, PAA nanogels were synthesized with a novel two-step procedure. The DLS analysis revealed that the more basic the $\mathrm{pH}$ solution, the larger the nanogel diameter was. The swollen state of PAA nanogel is characterized by an increased permeability, which favors the uptake or release of small molecules or proteins through the nanometersized meshes of the polymer network.

It was observed that uptake and release processes were driven by electrostatic and/or hydrophobic interactions, depending on the chemical nature of the solutes and on the $\mathrm{pH}$ of the external solution. In particular, uptake and release of TF were scarcely affected by $\mathrm{pH}$, as the TF uptake values at $\mathrm{pH}$ 4.5 and 7 were quite similar (38.2 and $46.4 \%$,

TABLE I

Encapsulation Efficiency (E.E.) Values Calculated According to the Following Formula: $\operatorname{EE~}(\%)=\left(W_{\text {en }} / W_{\text {tot }}\right) * 100$

\begin{tabular}{cc}
\hline Sample & E.E. (\%) \\
\hline OTF uptake (pH 4.5) & 38.2 \\
OTF uptake (pH 7) & 46.4 \\
BSA-OTF uptake (pH 4.5) & 98.4 \\
BSA-OTF uptake (pH 7) & 21.8 \\
\hline
\end{tabular}


respectively). These data can be explained by supposing that uptake and release of the nonpolar TF proceed throughout hydrophobic interactions with the lipophilic domain of the nanogel. Conversely, the uptake values of BSA-OTF were far different by running the experiments at $\mathrm{pH} 4.5$ and 7 (98.4\% and $21.8 \%$, respectively). These data suggest that uptake and release for the hydrophilic and $\mathrm{pH}$-sensitive BSA-TF occurred mainly via ion-exchange mechanism, in a strictly $\mathrm{pH}$-dependent way. Hence, it was possible to exert the control over uptake and release processes of oligothiophene-based fluorophores by changing the $\mathrm{pH}$ of the external solution. As the $\mathrm{pH}$ was varied in a quite physiological range, PAA nanogel resulted a suitable carrier for TF and its albumin conjugate. These results suggest that nanogels bearing either free TFs or their conjugates with proteins could be carried through organs and tissues for site specific staining.

The authors are grateful to Alessandra Quarta and Riccardo Di Corato and Mediteknology srl for providing the compounds used in this study.

\section{References}

1. Gaumet, M.; Vargas, A.; Gurny, R.; Delie, F. Eur J Pharm Biopharm 2008, 69, 1 .

2. Oh, J. K.; Drumright, R.; Siegwart, D. J.; Matyjaszewski, K. Prog Polym Sci 2008, 33, 448.

3. Oh, J. K.; Siegwart; D. J.; Lee, H.-I.; Sherwood, G.; Peteanu, L.; Hollinger, J. O.; Kataoka, K.; Matyjaszewski, K. J Am Chem Soc 2007, 129, 5939 .

4. Vinogradov, S. V.; Bronich, T. K., Kabanov, A. V. Adv Drug Deliv Rev 2002, 54, 135.

5. Peppas, N. A.; Bures, P.; Leobandung, W.; Ichikawa, H. Eur J Pharm Biopharm 2000, 50, 27.

6. Peppas, N. A.; Hilt, J. Z.; Khademhosseini, A.; Langer, R. Adv Mater 2006, 18, 1345.

7. Yallapu, M. M.; Reddy, M. K.; Labhasetwar, V. In Biomedical Applications of Nanotechnology; Labhasetwar, V., Ed.; Wiley: Hoboken, NJ, 2007; Chapter 6.

8. Tanaka, T.; Fillmore, D.; Sun, S. T.; Nishio, I.; Swislow, G.; Shah, A. Phys Rev Lett 1980, 45, 1636.

9. Langer, R.; Peppas, N. A. AIChE J 2003, 49, 2990.

10. Saunders, B.; Crowther, H.; Vincent, B. Macromolecules 1997, $30,482$.

11. Sawai, T.; Yamazaki, S.; Ikariyama, Y.; Aizawa, M. Macromolecules 1991, 24, 2117.

12. Portney, N. G.; Ozkan, M. Anal Bioanal Chem 2006, 384, 620.

13. Chalasani, K. B.; Russell-Jones, G. J.; Yandrapu, S. K.; Diwan, P. V.; Jain, S. K. J Control Release 2007, 117, 421.

14. Gümüşderelioğlu, M.; Kesgin, D. Int J Pharm 2005, 288, 273.

15. Qiu, Y.; Park, K. Adv Drug Deliv Rev 2001, 53, 321.

16. Cheung, C. Y.; Murthy, N.; Stayton, P. S.; Hoffman, A. S. Bioconjugate Chem 2001, 12, 906

17. Murthy, N.; Robichaud, J. R.; Tirrell, D. A.; Stayton, P. S.; Hoffman, A. S. J Control Release 1999, 61, 137.
18. des Rieux, A.; Fievez, V.; Garinot, M.; Schneider, Y.-J.; Préat, V. J Control Release 2006, 116, 1.

19. Kreuter, J. Adv Drug Deliv Rev 1991, 7, 71.

20. Hughes, G. A. Nanomedicine 2005, 1, 22.

21. Hu, Y.; Jiang, X.; Ding, Y.; Ge, H.; Yuan, Y.; Yang, C. Biomaterials 2002, 23, 3193.

22. Changez, M.; Koul, V.; Dinda, A. K. Biomaterials 2005, 26, 2095.

23. Yan, X.; Gemeinhart, R. A. J Control Release 2005, 106, 198.

24. Vinogradov, S. V.; Batrakova, E. V.; Kabanov, A. V. Bioconjugate Chem 2004, 15, 50.

25. McAllister, K.; Sazani, P.; Adam, M.; Cho, M. J.; Rubinstein, M.; Samulski, R. J.; DeSimone, J. M. J Am Chem Soc 2002, 124, 5198.

26. Yan, C.; Elaissari, A.; Pichot, C. J Biomed Nanotechnol 2006, 2, 208.

27. Barbarella, G.; Zambianchi, M.; Pudova, O.; Paladini, V.; Ventola, A.; Cipriani, F.; Gigli, G.; Cingolani, R.; Citro, G. J Am Chem Soc 2001, 123, 11600.

28. Barbarella, G.; Zambianchi, M.; Ventola, A.; Fabiano, E.; Della Sala, F.; Gigli, G.; Anni, M.; Bolognesi, A.; Polito, L.; Naldi, M.; Capobianco, M. Bioconjugate Chem 2006, 17, 58.

29. Zambianchi, M.; Barbieri, A.; Ventola, A.; Favaretto, L.; Bettini, C.; Galeotti, M.; Barbarella, G. Bioconjugate Chem 2007, 18, 1004.

30. Kappe, C. O.; Dallinger, D. Nat Rev Drug Discov 2006, 5, 51.

31. Vinogradov, S. V.; Kohli, E.; Zeman, A. D. Pharm Res 2006, 23, 920.

32. Bontha, S.; Kabanov, A. V.; Bronich, T. K. J Control Release 2006, 114, 163.

33. Bromberg, L.; Temchenko, M.; Hatton, A. Langmuir 2002, 18, 4944.

34. Eichenbaum, G. M.; Kiser, P. F.; Dobrynin, A. V.; Simon, S. A.; Needham, D. Macromolecules 1999, 32, 4867.

35. Kiser, P. F.; Wilson, G.; Needham, D. Nature 1998, 394, 459.

36. Kiser, P. F.; Wilson, G.; Needham, D. J Control Release 2000, $68,9$.

37. Chern, C. S. Prog Polym Sci 2006, 31, 443.

38. Guo, H.; Hamielec, A. E.; Zhu, S. J Appl Polym Sci 1997, 66, 935.

39. Liu, J.; Li, L. Eur J Pharm Sci 2005, 25, 237.

40. Liu, P.; Davis, P.; Liu, H.; Krishnan, T. R. Eur J Pharm Biopharm 1999, 48, 85.

41. Garcia, R.; Tamayo, J.; Paulo, A. S. Surf Interface Anal 1999, $27,312$.

42. Eichenbaum, G. M.; Kiser, P. F.; Simon, S. A.; Needham, D. Macromolecules 1998, 31, 5084.

43. Zhong, H.; Xu, J.-J.; Chen, H.-Y. Talanta 2005, 67, 749.

44. Janado, M. In Aqueous Size Exclusion Chromatography; Dublin, P. L., Ed.; Elsevier: Amsterdam, 1988.

45. Helfferich, F. Ion Exchange; McGraw-Hill: New York, 1962; p 151.

46. Ricka, J.; Tanaka, T. Macromolecules 1984, 17, 2916.

47. Li, J. R.; Henry, G. C.; Garno, J. C. Analyst 2006, 131, 244.

48. Missirlis, D.; Kawamura, R.; Tirelli, N.; Hubbell, J. A. Eur J Pharm Sci 2006, 29, 120.

49. Quan, C.-Y.; Sun, Y.-X.; Cheng, H.; Cheng, S.-X.; Zhang, X.-Z.; Zhuo, R.-X. Nanotechnology 2008, 19, 275102.

50. Dou, H.; Tang, M.; Yang, W.; Sun, K. Colloid Polym Sci 2007, 285,1043

51. Shi, L.; Khondee, S.; Linz, T. H.; Berkland, C. Macromolecules 2008, 41, 6546. 